\title{
A taxonomy of virtual worlds usage in education
}

\section{Ishbel Duncan, Alan Miller and Shangyi Jiang}

Ishbel Duncan and Alan Miller are lecturers in the School of Computer Science, University of St Andrews and have research interests in virtual world learning. Shangyi Jiang gained an MSc in Management and IT from the University of St Andrews and now works for Intel in China. Address for correspondence: Dr Ishbel Duncan, School of Computer Science, University of St Andrews, North Haugh, St Andrews, KY16 9SX, Scotland. Email: \{I Ishbel.Duncan@st-andrews.ac.uk, Alan.Miller@st-andrews.ac.uk, charlesjsy@gmail.com\}

\begin{abstract}
Virtual Worlds are an important tool in modern education practices as well as providing socialisation, entertainment and a laboratory for collaborative work. This paper focuses on the uses of virtual worlds for education and synthesises over 100 published academic papers, reports and educational websites from around the world. A taxonomy is then derived from these articles, delineating current theoretical and practical work on Virtual World usage, specifically in the field of education. The taxonomy identifies rich veins of current research and practice in associated educational theory and in simulated worlds or environments, yet it also demonstrates the paucity of work in important areas such as evaluation, grading and accessibility.
\end{abstract}

\section{Introduction}

Internet technologies have been deployed in business, education and academic life. Visual environments have developed from the original online games of over 40 years ago. Multi User Dungeon (MUD) games were developed in the 1970s (Bartle, 1990). By the 1990s fully graphical multimedia MUD Object Oriented systems had been developed along with Multi Player Online Games (MMOGs). One of the most widely known MMOG is World of Warcraft, (http://www.worldofwarcraft.com) with over 11 million active subscriptions.

Visual environments have been developed further from 3D Web-based technologies to form Multi-user Virtual Environments (MUVEs) such as Second Life and Active World (http://secondlife.com/; www.activeworlds.com). A MUVE enables multiple simultaneous participants to access virtual contexts, interact with digital artefacts, and represent themselves through avatars (online persona), communicate with other participants, and take part in experiences incorporating modelling and mentoring about problems similar to those in a real world context (Dieterle \& Clarke, 2005). A virtual world, by comparison, is also a computerbased simulated environment but which may not have multiple users playing simultaneously online. According to Mennecke (2008), virtual worlds are part of the domain of multiplayer online games but without the organised game play. A virtual world could be entered on an off-line personal computer, such as with the game Sims (http://thesims.ea.com/en_us/home), but a MUVE implies on-line interaction with other users.

MUVEs allow multi users to access 3D virtual environments at the same time. The use of MUVEs has not only attracted gamers who enjoy exploring on-line virtual worlds, but also businesses and academic researchers. The educational use of MUVEs has become a key area of research (Bellotti, Berta, De Gloria, \& Primavera, 2010; Edirisingha, Nie, Pluciennik, \& Young, 2009; Falloon, 2010; Hew \& Cheung, 2010; Jestice \& Kahai, 2010; Oliver \& Carr, 2009; Petrakou, 2010; Salmon, 2009). 


\section{Practitioner notes}

What is already known about this topic

- The use of virtual worlds for supporting education is widespread and increasing.

- There are numerous studies virtual worlds usage in education.

- Virtual worlds are mainly used for collaborative- or simulation-based education.

\section{What this paper adds}

- An analysis and synthesis of over 100 academic papers and virtual worlds,multi-user virtual environments and virtual learning environments.

- A taxonomic differentiation based upon population, educational activity and learning theory.

- A balance sheet of the disadvantages and advantages of using virtual worlds in education.

- Identification of under developed areas of research into virtual worlds in education.

\section{Implications for practice and/or policy}

- Motivates the use of virtual worlds to support experiential learning, where real world experiential learning is difficult to achieve due to barriers of time, cost and place.

- Identification of difficulties and challenges in the educational use of virtual worlds.

These may be overcome through future work or help identify where the use of virtual worlds is not appropriate.

- Identification of where the current development or research focus is: pedagogy, collaboration, enquiry-based learning and identity, etc.

Another virtual environment with the specific purpose of enabling teaching and learning is the Virtual Learning Environment (VLE). A VLE usually includes educational documents, assessment uploading and tools as well as a communication facility between tutors and students (Jenkins, Browne, \& Walker, 2005). The history of VLEs is long with some computer based courses developed as early as the 1960s, but the computer advances of the 1980s and 1990s allowed the creation of learning systems that are recognisable today as Internet based media. A comparison table of virtual worlds, MUVEs and VLEs shown in Table 1 demonstrates that VLEs are dedicated to educational improvement whereas virtual worlds and MUVEs are similar and are often considered as one type. In this table it is presumed that an example of a virtual world would be the Sims game mentioned above, whereas a MUVE would be World of Warcraft where players can interact on-line to attain goals. As there are many similarities between MUVEs and virtual worlds, we use the term virtual world generically in this paper, to encompass any online virtual environment that allows users to play, learn or interact.

Use of the Internet has grown to over 2.095 billion worldwide (March 2011 figures) with penetration (\% of population) at 58.3\% for Europe (476 million people on-line) and $78.3 \%$ for North America (272 million people on-line). Asia has $23.8 \%$ penetration (922 million people online) but because of its large population it accounts for $44.0 \%$ of the total Internet population, a figure that has been rising over many quarters (www.internetworldstats.com). These figures demonstrate that any improvement in online educational techniques, derived from the use of virtual worlds or similar environments, will have a high impact on the world-wide on-line population.

After a short overview of the predominant virtual world currently in use, Second Life, is given, ataxonomy of virtual world educational uses is presented. Categories of the taxonomy are validated with examples from the 100 articles reviewed for this work. 


\begin{tabular}{|l|l|l|l|}
\hline & Virtual World & MUVE & VLE \\
\hline Educational purpose & & & Y \\
\hline Tutor Feedback & & & Y \\
\hline $\begin{array}{l}\text { Directed/ Managed } \\
\text { Learning }\end{array}$ & & & Y \\
\hline Syllabus & & & Y \\
\hline Course Administration & & & Y \\
\hline Tutor Authoring Tools & & Occasionally & Y \\
\hline Notice Board Access & Occasionally & & Y \\
\hline Educational Tutorials & & & Y \\
\hline Assessment real or & & & Y \\
\hline Publishing (upload) & & & Y \\
\hline $\begin{array}{l}\text { Differential } \\
\text { Rights }\end{array}$ & & & Y \\
\hline Usage Tutorials & Y & Y & Y \\
\hline $\begin{array}{l}\text { Access Virtual Contexts } \\
\text { representing real } \\
\text { imagined worlds }\end{array}$ & Y & & Y \\
\hline $\begin{array}{l}\text { Experience real } \\
\text { imagined world events }\end{array}$ & & Y & Occasionally \\
\hline $\begin{array}{l}\text { Model real or imagined } \\
\text { world events }\end{array}$ & Occasionally & Y & Occasionally \\
\hline 3D space & Y & Y & Occasionally \\
\hline Act with other users & Occasionally & Y & Yccasionally \\
\hline Chat system Acmally \\
\hline Use of an Avatar & Y & & \\
\hline Quality Control & Occasionally & & \\
\hline
\end{tabular}

Table 1: A comparison of VW, MUVE and VLE attributes.

\section{Second Life}

The Centre for Learning and Performance Technologies lists Second Life as the top Virtual World for education use (http://c4lpt.co.uk/recommended/2010binb.html). In 2003, the Linden Lab launched the very first version of Second Life. In 2004, Second Life was re-launched with more functionality. In the last decade researchers have shown great interest in using 3D based VWs, especially Second Life (SL), as a new aid to teaching.

Second Life is based on mark-up languages such as HyperText and Virtual Reality Mark-up Languages (HTML and VRML), which allow creation and display of 3D objects on the web. Visually, SL is a 3D simulation of the real world; there are islands and oceans, buildings and gardens. Almost everything you can find in the real world has their SL equivalent. One of the unique points of SL is that it allows content creation by its users. Archaeologists can build models of ancient sites where one can view completed ancient structures and biologists can visualise cell structures that can be navigated. Linden Labs manages the virtual world and has created some items in-world such as roads and some library items such as avatars (people) that can be 
personally adapted. What we see today in SL is mainly created by the users of SL (Kirkpatrick, 2007). Ordinary users can enter SL for free as they only have to pay real money if they wish to buy virtual articles for their avatars or islands. The latter are computer servers in the real world which store the required information.

Since Second Life opened, the number of residents has grown to more than 300 million residents registered in the system (Hays, 2008) however, the number of users that have regularly logged in is much less. Statistics collected by the Linden Lab (www.Secondlife.com) shows the most recent average monthly repeat logins to be around 795,000 with the quarterly user hours spent on Second Life over 105 million hours in the last quarter of 2010.

As it becomes increasingly popular, Second Life usage becomes more varied. SL usage can be divided into categories such as educational or business use and, separately, social communities usage. Examples are the EducationUK Island, the Intel Corporation and the SL Music Community. For educational use, there are many in-world educational events that teach various skills, such as language teaching, scientific enquiry skills, medical skills etc.. Education UK is one of the education islands in-world facilitating a variety of educational activities. There are many companies that have invested in Second Life, such as IBM and NIKE. These companies have purchased islands, computer server storage, for their businesses within Second Life and built simulations (Sims) of their company to give a visual presence to the visitors. The purposes of using SL for businesses are varied; some are simply using it as an advertisement, others make sales within Second Life, some use it for training purposes and others recruit new staff via interviews. On-line communities are another popular use of SL for socialising in-world. Any user can join these communities, socialise and entertain or perform some enquiry of other communities. Hew and Cheung (2010) surveyed 15 papers and noted that virtual worlds can be utilised for communication spaces, simulation of special areas and experiential spaces that allowed avatars to act on the world.

\section{A virtual world educational taxonomy}

As noted in the Introduction, we use the term virtual world to encompass VLEs, MUVEs, MMOGs etc all of which have an online presence and can be used for play, learning or social activities. Much published research has focussed on experimenting and evaluating Virtual Learning Environments, and many articles have been written on different aspects of the educational uses (Akpan \& Brooks, 2005; Childs, 2007; Dawley, 2009; Hew \& Cheung, 2010; Jestice \& Kahai, 2010; Mason, 2007; Petrakou, 2010). For this paper, a review was performed of virtual worlds, tools and techniques which enabled or facilitated Internet based educational support. This was done over four separate periods totalling over six months in each year from 2008 to 2011. Through Google Scholar, the Association for Computing Machinery's Digital Library, the ACM Portal, and electronic journals available through the University of St Andrews Library, all Computer Science, Information Technology and Computer Education academic journals, conference articles and online reports were searched for reference to the following keywords and phrases; virtual worlds, MUVEs, VLEs, online education theory and practice and virtual world educational support technologies. A total of over 90 virtual worlds, technical reports and academic papers were examined. During the research it was noted that there were similarities in six distinct categories of the published works and a more detailed analysis of these articles is given later in this paper under the section heading Analysis of the surveyed literature. The categories form the primary level differentiators of the Virtual World Educational Usage Taxonomy and each can be subdivided further as discussed in the following sub-sections. The first five of these categories map onto the five basic enquiries of Who (Population), What (Educational Activity), Why (Learning Theory), Where (Learning Environment) and How (Supporting Technologies). The Research Areas category covers case studies or other areas of interest, which in themselves may be theoretical, practical or technical. Classified according to the content or influence in online education, these six categories are: 
- Population: Who the users are and the discipline, e.g. medical students aged 18+

- Educational Activities: What activities the users are performing, e.g. running a simulation of an archaeological dig to learn the processes involved or walking through a 3D representation of a cathedral to understand construction techniques

- Learning Theories: Why the users are doing particular activities, e.g. constructivist or collaborative learning to understand how a cathedral was built

- Learning Environment: Where the users are working, e.g. inside a simulation of a temple

- Supporting Technologies: How the system supports the users, e.g. audio, bandwidth, display or tactile equipment.

- Research Areas: Other cases of learning specific research, e.g. case studies or research on usability, grading or evaluation.

\section{Population:}

The Population category distinguishes the group commonly using these virtual environments for education. This category was created because, depending on the targeted users (learners), the selected virtual environment may be different, such as under 18s can only use Teen Second Life. Also, the designed activities and Learning Theories used within the experimental projects may be different between age groups or different types of users, for example those with learning disabilities. Different populations will require different support technologies or experiences, for example, in a lifelong study for elderly people, more audio might be used rather than keyboard interaction and more instructional design used rather than problem based learning.

There are six elements of age based population; primary education, high school education, college (further) education, university education, life-long education and general education. This is more detailed than the Rix and Twining (2007) typology where they define three levels of up to 18, post 18 and lifelong. Other elements in this category are hearing or sight impaired and learning or physically disabled.

Other works associated with the Population category include (Boulos, Hetherington, \& Wheeler, 2007; Joseph, 2007; Trewin, Laff, Cavander, \& Hanson, 2008)

\section{Educational activities}

This category contains the separate types of activities that have been used within virtual worlds as a way of teaching and learning including;

- Problem Based Learning

- Enquiry Based Learning

- Game Based Learning

- Role Playing

- Virtual Quests

- Collaborative Simulations (learn by simulation)

- Collaborative Construction (building activities)

- Design Courses (Game, Fashion, Architectural)

- Language Teaching and Learning

- Virtual Laboratories

- Virtual Field Works

- Attending lectures or classes

These elements of educational activities are used within the educators' designed projects, and are based on different learning theories. The activities are not dissimilar from the ones that have been used in normal classroom education. Kay and Fitzgerald (2008) suggest a larger list of activities 
which is more specific than the categorical one above. Myller et al. (2009) present an Engagement Taxonomy which has relevance here. Some of the above activities may involve simple viewing (of information), others may require responding, changing, constructing or presenting. This reduces to no engagement, passive engagement and active engagement. Most of the activities described in the reviewed literature fall into the active engagement category but class attendance online, as in the real world, is considered passive engagement.

Other works associated with the Educational Activities category include (Alarifi, 2008; Getchell, et al., 2006; Getchell, Miller, Allison, \& Sweetman, 2008; Roussou, 2004)

\section{Learning theories}

The term Learning Theory is used here to refer to the philosophy behind the general approaches of educational activities. The use of VWs as an educational tool is still under development; separate teams of researchers are applying a range of educational strategies and methodologies when performing experiments, trying to determine the most suitable pedagogy, and andragogy, for in-world education. According to current research (Twining, 2009), experiments have been performed by integrating different learning theories into educational activities and course design. Not surprisingly, constructivist techniques such as problem based learning and collaboration and, separately, game based activities are common practices used in VW education as they allow experiential learning. By developing scenarios which involve group work activities, educators can help learners benefit from the strengths or interests of other team members and ultimately develop their own skills and confidence levels. Computer games can encourage learners to be interactive and allow for discussion based on game planning and strategy, as well as increasing student confidence.

An array of collaborative tools is available in VWs, especially VLEs and MUVEs; wikis, blogs, collaborative document tools social networking as well as learning management systems. It is therefore not surprising that didacticism (direct instruction) is little used in the surveyed papers, although some use is made of avatar face -to- avatar face teaching or presentation.

The supporting literature identifies distinct divisions of Learning Theory practices: problem based learning, collaborative, experimental, experiential, instructional, constructivist, didactic and interactive. However, if the classification is reviewed in terms of student learning, the scale would be from didactic at the most lecturer intensive end (student passive engagement) to knowledge building constructivist at the most student active end (student active engagement). Twining (2009) also provides a further element to the practice of learning, that is, the level of immersion in the virtual world. Jestice and Kahai (2010) suggest that virtual worlds can offer unique experiences consistent with situated learning theory in which learning happens within the applied context and learning is active and acquired through experience. Jarmon et al. (2009) discussed four research questions including how students learn in SL and whether the learning transfers into the real world. They concluded that SL is an effective environment for a project-based experiential learning approach because of the connection between the real world and the in-world tangible experience. However, they noted issues with communication and the SL learning curve.

Other works associated with the Learning Theories category include (Chalk, 2002; Dawley, 2009; Falloon, 2010; Mason, 2007; Richter, Anderson-Inman, \& Frisbee, 2007)

\section{Learning environment}

Individual institutions or research groups have used a variety of applications as platforms for their projects. This category contains the different virtual environments that are used by these educators and researchers.

A Virtual Learning Environment (VLE) facilitates e-learning by supporting teaching and learning in an educational context over the Internet. These learning environments can be divided into two 
sub-categories. The first one is based on Web 2.0 to allow interaction between users. The Web 2.0 based VLEs are text based and known as Learning Management Systems (LMSs). Applications such as WebCT, Blackboard and Moodle belong to this category.

The second sub-category of application is based on 3D web technologies. These applications are normally created in 3D and provide the user with a visualized virtual world. Examples of VWs in this category are Second Life and Active World.

Other works associated with the Learning Environments category include: (Chalk, 2002; Petrakou, 2010; Richter, Anderson-Inman and Frisbee, 2007; Robbins, 2007)

\section{Supporting technologies}

These technologies are the ones integrated with the applications designed by the application providers, for instance, the technology of voice over the Internet protocol (VoIP), stream video/audio and Chat and Instant Message (IM) (Akpan \& Brooks, 2005). Head-Up Displays can be designed to display extra information or give extra avatar control. The uses of these supporting technologies vary and different supporting technologies can achieve a range of functionalities, such as communication, publishing, programming, navigation/mapping and immersion. They are chosen for separate educational projects and to achieve a range of purposes. For example, inworld lectures might use stream video or stream audio to help distribute course content, and inworld role play activities might use chat or instant messaging to improve the efficiency and effectiveness of communication. Getchell et al. (2010) discusses infrastructure, logic and an evaluation of a case study whereas Allison et al. (2010) discusses issues of bandwidth and port usage which affects the Quality of Service for virtual world usage. Smith-Robbins discusses ten different levels or types of communication in virtual worlds and concludes that these aspects may inform our notion of technological effectiveness. In her thesis (2011), Smith-Robbins details a classification of virtual worlds based on facets such as form of content, access to groups and environmental access.

Other works associated with the Supporting Technologies category include (Robbins, 2007; Sreedharan, Zurita, \& Plimmer, 2007)

\section{Research areas}

As the use of VWs as a virtual learning environment is very new, various aspects of using these virtual worlds in education are still under development. Researchers are experimenting on aspects of the use of VWs, such as identity, embodiment and geo-spatial representation. Institutionally, researchers are interested in usability and deployment as well as Learning Theory (Kelle \& García, 2007; Leidl \& Robling, 2007). Other challenges include knowledge passing and co-ordination issues in a learning environment. Petrakou (2010) suggests that students need to understand the social norms within a virtual world, which are different from real world interactions. She suggests that new rules for social interaction will emerge as students become familiar with virtual worlds and these need to be studied further. Hew and Cheung (2010) noted in their survey that research was either descriptive or experimental, with only one of the 15 papers surveyed describing experimental research. They noted that most research had been done in the Media Arts and Health and Environment areas and focused on learning outcomes, social interaction and the affective domain, that is, the student's attitude, values, feelings and satisfaction while exploring the virtual world. Hew and Cheung suggested that positive results were perhaps more attributable to the scenarios used than to the virtual world. Getchell et al. (2010) noted issues to do with virtual world scenario evaluation as well as usability.

Other works associated with the Research Areas category are: (Cheryan, Meltzoff, \& Kim, 2011; Gregory, et al., 2010; Smith-Robbins, 2011; Weusijana, Svihla, Gawel, \& Bransford, 2007) 


\section{A taxonomy of virtual worlds educational usage}

The six categories presented in the taxonomy are interrelated and split into three levels as demonstrated in Figure 1. The top level comprises the activities associated with Learning Theories such as theoretical and educator experiential work. The Population category relates directly to Learning Theory but also affects and directs Educational Activity, and hence straddles both the Theoretical and the Activity layers. Underpinning the Educational Activity are the Learning Environments and the Supporting Technologies which are both placed on the lowest, most technical layer. Supporting Technologies is also related to Population as disparate populations, such as the elderly or disabled, require different support mechanisms. The taxonomy is therefore formed of a Theoretical Layer, an Activity Layer and a Technical Layer. The sixth category is Research Activities and this incorporates general case studies and universal areas of research as well as including aspects of the other categories. The taxonomy not only demonstrates the inter-relationship of the categories but allows focus on any individual element within the system. Alternatively, a more holistic approach to $\mathrm{VW}$ research can therefore incorporate different categories within the same project.

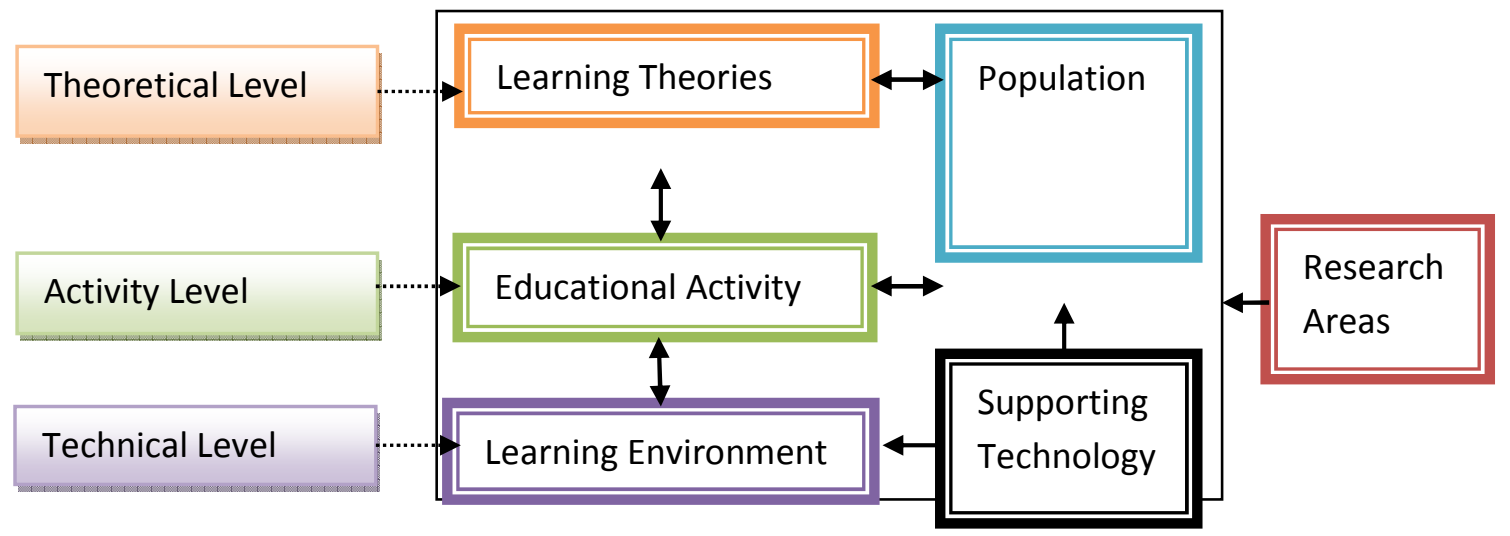

Figure 1: Hierarchy relationships between categories within the taxonomy

As an example, a particular teaching or research activity would be embedded within an environment and may have social aspects, simulations, workspace and technologies associated with it. See McKeown (2007) and Warburton (2009) for a typology of 3D virtual worlds that expand on the relationship between activity and environment.

In comparison with the Taxonomy of Digital Spaces (Robbins, 2007), Robbins concentrated on communication between users, the network and the environment. Effectively her taxonomy sits within the Learning Environment category described here. The work of Gregory et al (2010) uses the typology of Messinger et al (2008) based on Porter's original work (2004). In their typology, the categories are Purpose, Place, Platform, Population and Profit model. The first four translate, somewhat roughly, to our Learning Theories, Learning Environment, Supporting Technologies as well as Population. Messenger et al's Purpose elements are concerned with game theme or virtual world focus whereas the taxonomy presented here concentrates on the reasoning, the theory, behind why the virtual world is being used for educational purposes, that is the applicable modes of learning such as experiential, game play or constructive learning. Messinger et al's Place category is based on whether the world is totally or partially virtual and whether the players are geographically dispersed whereas we specifically consider the actual learning environment to be the Place of concern, essentially the world the users inhabit such as within www.schome.ac.uk, Smallworlds.com or www.Kaneva.com. We make no reference to profit model as our focus is on educational use, although profit is obviously necessary for non academic companies to provide virtual worlds. The Messinger et al work is also concerned with all virtual worlds whereas the focus in this research is on virtual worlds for educational support. 


\section{Analysis of the surveyed literature}

After reviewing over 100 papers virtual worlds or reports, listed at (http://www.cs.standrews.ac.uk/ ishbel/Research/TaxonomyBiblio.pdf), it was concluded that there were six different categories within the VW Educational Taxonomy.

Under the category of Population, most of the reviewed literature focused on higher and further education rather than on school pupils, the elderly or physically or mentally impaired.

The second category in the VW Educational Usage Taxonomy is named Educational Activities (Figure 2). This category describes the uses made of virtual worlds and demonstrates that Collaborative Simulation activities are the most common amongst educational researchers with around $46.2 \%$ of the reviewed literature using Simulation. The second biggest category is Collaborative Constructional activities with around 24 per cent of the published literature. Game based learning is discussed in as much as one fifth of the reviewed literature. Virtual quest is about $13.8 \%$ of the reviewed literature. The percentage of virtual field work, role play and lecture/classes are all around $10 \%$ to $20 \%$ and a virtual laboratory makes up only $6.2 \%$.

Under the Learning Environment category, most of the surveyed articles used Second Life as a platform for 3D Web based learning allowing virtual student interaction. For Web 2.0 based Virtual Learning Environments, Moodle, WebCT and Blackboard are used to facilitate learning and teaching.

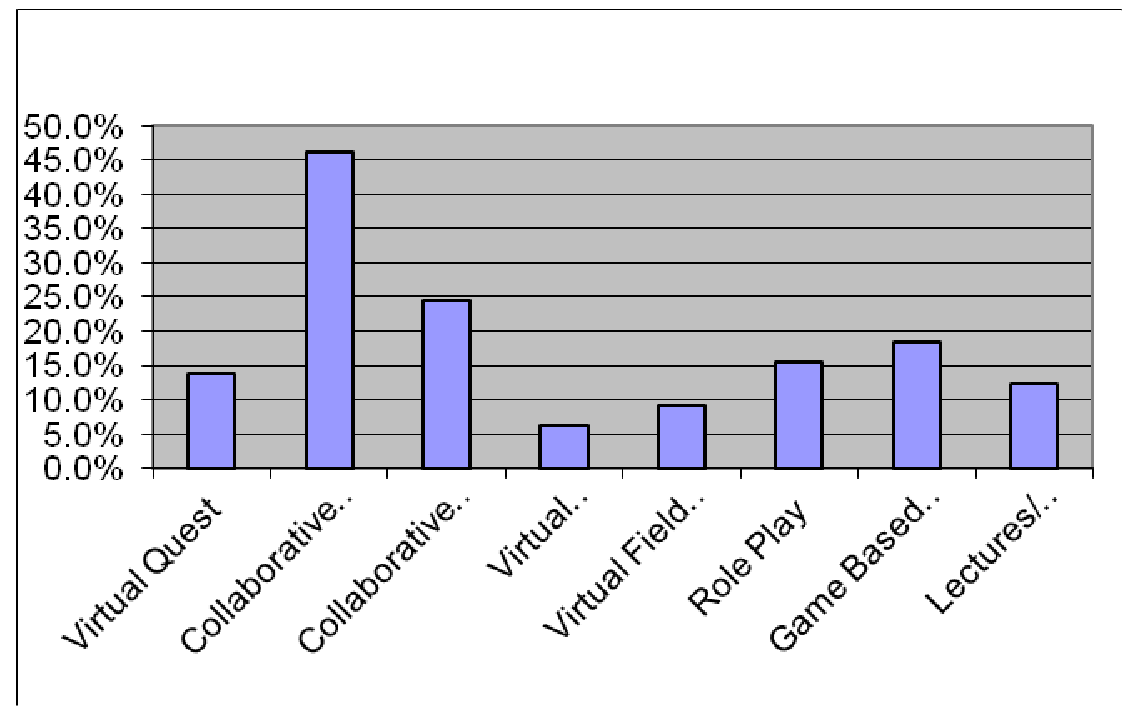

Figure 2 Summary of the educational activities in the reviewed literature

Figure 3 demonstrates the implementation of the different learning strategies, or Learning Theories, which is the fourth category of the presented taxonomy. Collaboration has been used most, with almost $60 \%$ of the reviewed articles. Many articles focused on both Experimental (30.8\%) and (knowledge building) Constructivism (40.0\%). Problem Based Learning (PBL), instructive learning, didactic learning and interactive learning have attracted less interest, with around $14 \%$ to $20 \%$ of reviewed publications. 


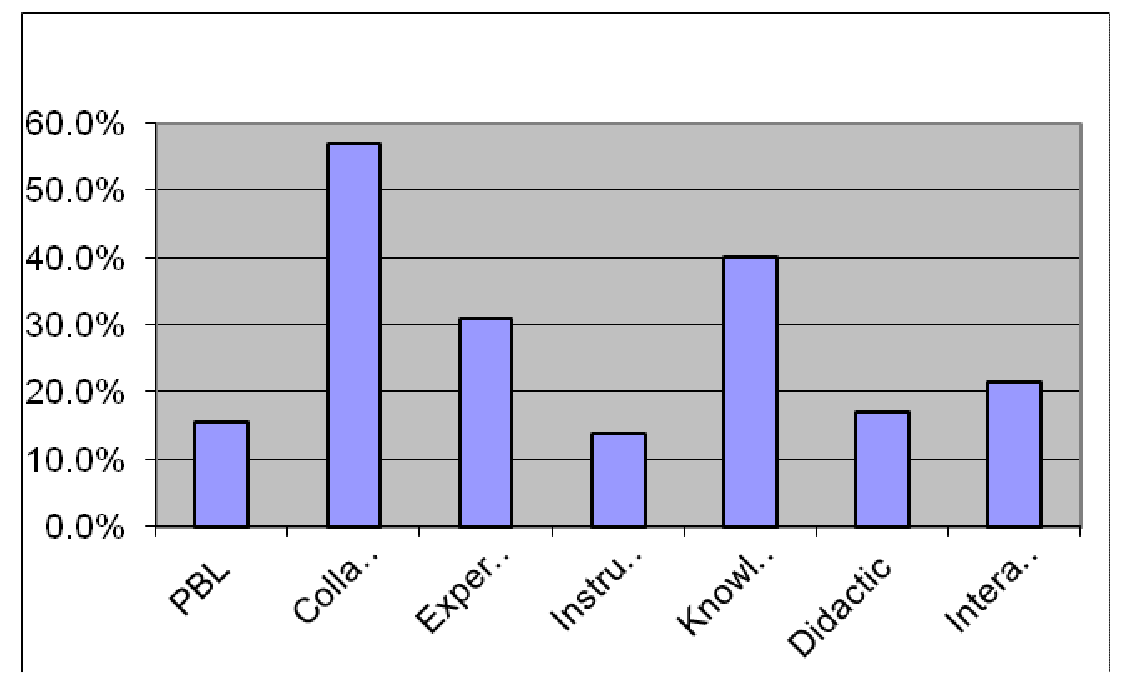

Figure 3 Summary of learning strategies in the reviewed literature

Among all the disparate Research Areas (Figure 4), educators have shown most interest in finding the most suitable learning strategy for in-world education. After distance learning, identity aspects (on-line persona and real identity) and usability are the most common research area. In order to make use of the VWs, some researchers focused on the system development of applications, aiming to optimize the application and the environment. As VWs are relatively new, embodiment, or the kinds of bodies used, has become an aspect of interest. The statistics of the reviewed literature shown in Figure 4 are approximately: 20\% for embodiment, 23\% for identity, 27.7\% for geo-spatial representative, $8 \%$ for institutional aspects, $60 \%$ for learning strategy, $17 \%$ for system development, $20 \%$ for usability and none for system development.

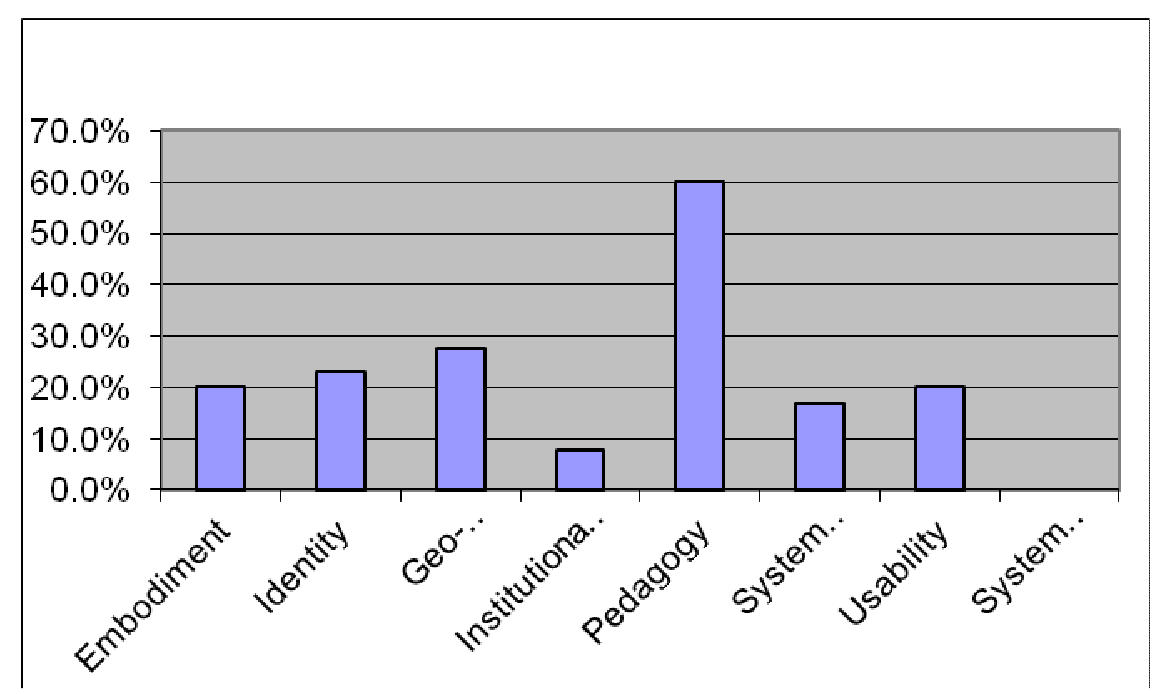

Figure 4 Summary of the research areas in the reviewed literature 


\section{State of the Art}

From the examples in the reviewed literature table, a pie chart was constructed to demonstrate the current status of research and teaching development. Figure 5 shows the state of development of the published examples; if they are based on theory, experiment, are under evaluation or are already deployed for regular teaching. None of these institutions have discussed theoretical work without doing any experimentation. Around $60 \%$ of the examples were doing experimental work, $3 \%$ of examples were deployed and the rest of them were under evaluation. Second Life was used in most of the cases to do their experiments. A variety of support technologies were used to facilitate these projects.

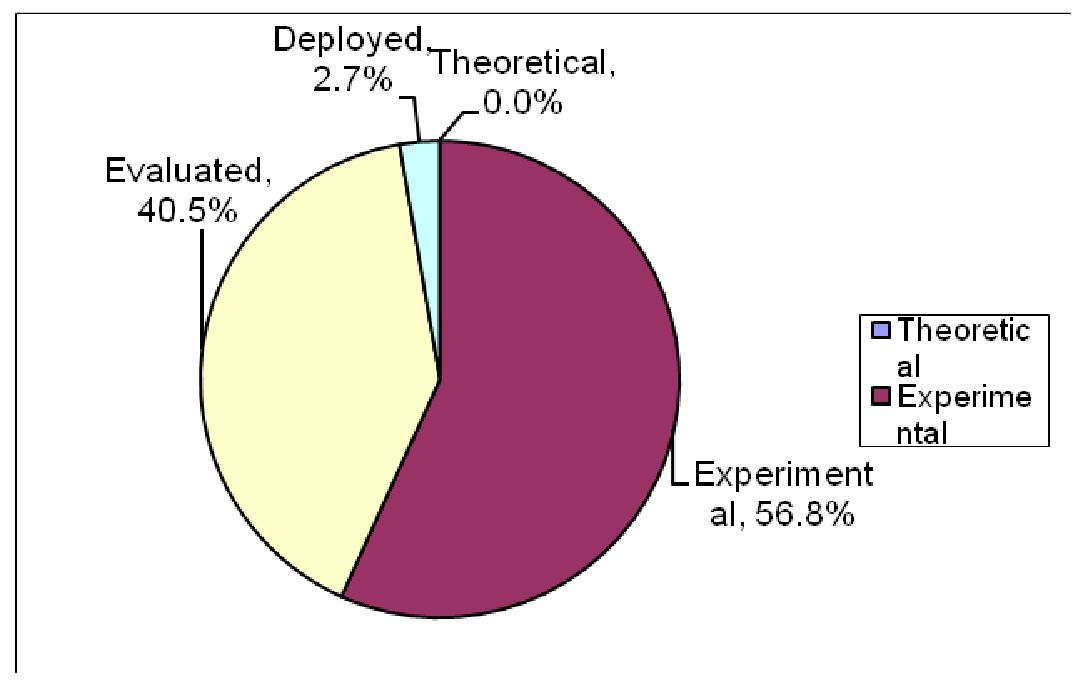

Figure 5 Summary of examples - their state of development

\section{Discussion}

The use of Second Life for educational purposes is still a novel field. SL is used for a variety of different activities designed to determine and expand the potential of VW usage in teaching. Much interest is focussed on finding the proper learning strategy for in-world teaching and learning. The geo-spatial representation characteristic of Second Life allows researchers to focus on the use of VWs for distance learning. However, the reviewed literature demonstrates both advantages and disadvantages in using VWs:

\section{Advantages:}

1. The use of Second Life provides an intuitive modern approach for distance teaching in terms of the use of avatars. Compared with traditional VLEs (such as Moodle) in distance learning, Second Life can use different supporting technologies such as VoIP and IM along with avatars to represent a simulation of a real-life education.

2. Collaboration is greatly facilitated when conducting educational activities in-world. Collaborations were widely used in a range of educational activities, for instance, activities using simulations and team based role play activities. When participants were learning activities in-world, the designers of the activities preferred to use the collaborative methodology of education because the communicational technologies inworld supported them well.

3. Experimental and Constructive learning can be achieved in Second Life. The use of prims (a primitive, or prim, is the encoding of a single part virtual object such as a coin) to build simulations provides an opportunity for learners to learn by doing experiments (in virtual laboratories) or constructing knowledge by themselves rather than being taught directly. 
4. (Falloon, 2010) states that higher order thinking, such as analysing, evaluating and creating, can be achieved in virtual worlds as well as lower order thinking, such as remembering, understanding and applying. If collaborative and experimental learning are the most common uses of virtual worlds then it demonstrates that educators are aiming for more higher order learning skills.

5. As the geographical boundaries are broken down in Second Life, there is a large diverse background among participants. An example of this would be the case of the MSc course in E-Learning at Edinburgh (http://www.education.ed.ac.uk/e-learning/). Participants of the course are geographically separated, as there is no need to come to a specific location in real world. Students with different nationalities in geographically separate countries can participate in the course at the same time.

6. It is possible that the in-world activity is always more interactive than real-world teaching activities (Macías-Díaz, 2008a). The same lecture style teaching was conducted in-world and in the real world, and the participants were more active in the virtual world. The use of Chat and IM technologies removed the fear of students talking in public. Also, for international students whose first language is not English, they processed the information better when reading the chatting histories. Further, virtual worlds can enable and enhance social interactions (Falloon, 2010).

7. The LAVA project conducted by the School of Computer Science at St Andrews University shows the potential of virtual field work to assist teaching (Getchell, et al., 2006). The use of simulation to recreate the Basilica site achieves educational goals that are hard to achieve in the real world. Virtual simulations and virtual excavation activities can achieve desired educational objectives. As (Falloon, 2010) notes, virtual worlds are ideal for constructing authentic feature risk tasks which would be difficult to do in the real world due to resource constraints such as cost or access to location.

8. When using Second Life to build Virtual Labs and conduct discovery and knowledge building activities there is some positive feedback (Macías-Díaz, 2008b).

\section{Disadvantages:}

1. Second Life is based on 3D Web-based technologies and therefore requires computers with high specifications, especially graphic cards and high RAM (main memory). Internet broadband speed is also crucial to the use of Virtual Worlds. If the Internet connection is not fast enough there will be a lot of lag and downtime. Computers may freeze and crash because of the power demand.

2. When participating in activities in-world, students sometimes found it is hard to concentrate on the learning activity (Macías-Díaz, 2008b). The virtual world has too much functionality and the different Sims in-world distract the attention of participants.

3. As students learn and participate virtually, it may be hard for educators to monitor the educational process. It is hard to tell if the students are actually learning or playing in the VWs. According to the St Andrews case study (Macías-Díaz, 2008b) feedback shows that the lecturers could observe the performance of students via their avatars' body language. However, compared with traditional class style teaching, the in-world expressions are not as intuitive as the expressions educators received in classroom. Moreover, the virtual expression shown in-world might not be trustable or recent.

4. In-world activities such as building objectives using prims, seems to have no value for students. Building within Second Life might have no value or relationship to the students' real life world.

5. The use of virtual simulation for teaching purposes might be challenged by the use of simulation in the real world. For example the Carnegie Mellon University entertainment technology centre is a large simulation laboratory (Pausch \& Marinelli, 2007). Comparing this centre to virtual ones such as the medical practise training centre at the Virtual University of Edinburgh (http://vue.ed.ac.uk) and other simulations (Sturgeon, Miller, \& Allison, 2008), people will naturally prefer the more realistic environment.

6. (Petrakou, 2010) suggests that Second Life is not adequate as a teaching resource because additional context information is required which is distracting. This is in direct contention 
with (Bellotti, et al., 2010) who suggest that virtual worlds should embed a lot of high quality contextualised information so that the student player can gain as much as possible from their explorations.

7. (Jestice \& Kahai, 2010) noted that some virtual world participants found that their first visit was too overwhelming and unguided to provide a meaningful experience. Finding a balance between free ranging activities and guided set pieces is a narrow path to tread.

8. (Petrakou, 2010) states new students are unaware of social norms within a virtual world and require some understanding of language usage and gesturing. The use of "freer" language was often noted by researchers.

9. (Jestice \& Kahai, 2010) state that simply using a virtual world is not sufficient to improve cognitive outcomes. Whereas students reported higher perceived learning and satisfaction with learning, their overall performance for declarative knowledge was actually much lower than non virtual world learners.

Overall, these different and, to some extent, differing advantages and disadvantages are created by the use of new web technologies. The development of VWs such as Second Life is still at the early stage. The potential and effective use and manipulation of these environments is still under research. A limitation of the analysis is that is has been performed early in the current trend for virtual world learning. Whereas it is useful to determine trends, educational uses, applicable learning theories and supporting technologies, these will undoubtedly change over the coming decade as researchers and educators become more adept at using the rich virtual world media.

\section{Future Research}

As a new field of education, there are different areas of research which can be expanded on in the future:

- On the technology side, usability research is a key area of current, and no doubt future, research. Currently, the operation of an avatar is done by using a mouse and keyboard, but the development of immersion technology such as 3D haptic input equipment (video helmet, gloves etc.) can change the way people use VWs. Motion detection and interaction hardware and software such as used in the Xbox Kinect (http://www.xbox.com/en-gb/kinect) will no doubt become more endemic and allow easier control of avatars and environment. The lag and downtime in Second Life is still a significant drawback for its educational use but higher speed broadband and graphics cards will reduce that. Current development of Second Life aims to reduce these technological problems.

- An in-world identity is represented by using an avatar, but the in-world behaviour might be different from the user in the real-world. To have a good understanding of the user's in-world behaviour could help develop the educational use of VWs.

- Research looking at the disparate uses of Second Life and the institutional uses of Second Life could be explored more. Research could be carried out to find the most suitable learning theory and applicable strategy for in-world course design and practice.

- When teaching in-world, educators may find it hard to monitor student learning. Better mechanisms need to be developed to ensure that students have effective learning practices and that they are measured accordingly, given the known research issues of cohort analysis and observational difficulties.

- Appropriate assessment and evaluation methods should be developed to ensure individual and group needs are addressed.

- The issue of contextual information; how much is given and where is it to be displayed has to be addressed.

- Inclusion and accessibility has to be addressed by more researchers; the use of virtual worlds (for education) should not disadvantage particular social, minority or disabled groups.

- Research could focus on the delivery of in-world skills applicable to the real world, that is, how students transfer their knowledge gained in the virtual world to real life. Many students found it hard to determine the benefits of creating things in the virtual world. How educators 
could change this situation, and make use of activities that are created for real life value could be discussed.

\section{Conclusion}

VLEs and MUVEs have shown great potential in teaching and learning and are a valuable contribution for collaborative or problem based learning. Researchers and educators are using these new tools in traditional and familiar ways but the full potential of the use of virtual worlds in education is still to be utilised. Now that the game based hype of virtual worlds is over, researchers are well placed to appropriate and evaluate the blended learning resulting from virtual and real world classrooms and laboratories. The strongest examples of the use of these virtual tools are problem based learning or constructivist activities such as in Computer Science simulations of network routing algorithms and in Archaeological fieldwork simulations. These dedicated virtual worlds are a strong support for group work and learner interaction, allowing geographically separate students to be aware of other people in-world with the same interests. However, an area of concern is virtual world education for the physically and socially disadvantaged which is lagging behind other areas of research.

The presented taxonomy, derived from current work around the world, indicates that there are several areas of potential research and development including appropriate educational activities, suitable learning environments, correct supporting technologies, revised learning theories, experimental and verifiable evaluation practices for all population groups. The taxonomy was developed to indicate not only categories of current VW research and practice, but also to demonstrate where that work is concentrated. As each of the six categories of the taxonomy is a distinct research area, this paper demonstrates the need for both finely grained categorical work as well as a holistic approach to research and practice in virtual education, encompassing multiple categories of the taxonomy. Further, as virtual world educational usage is in a nascent state, a future survey will no doubt demonstrate changing trends based on technology availability, speed and cost, the requirement for geographically separated teaching and hopefully a more inclusive approach to all age and social groups and physical abilities. A more fine grained research survey is recommended within five years to elicit trends and advances in this fast moving field.

\section{References:}

Akpan, J. I., \& Brooks, R. J. (2005). Experimental Investigation of the Impacts of Virtual Reality on Discrete-event simulation. Paper presented at the Winter Simulation, Orlando, Florida.

Alarifi, S. A. (2008). An Exploratory Study of Higher Education Virtual Campuses in Second Life. University of Nottingham, M.A. Thesis, Nottingham, UK.

Allison, C., Miller, A., Sturgeon, T., Nicoll, J. R., \& Perera, I. (2010, October 2010). Educationally Enhanced Virtual Worlds. Paper presented at the 40th ASEE/ IEEE Frontiers in Education Conference, Washington D.C.

Bartle, R. (1990). Early MUD History. Retrieved August 2008, from http://www.mud.co.uk/richard/mudhist.htm

Bellotti, F., Berta, R., De Gloria, A., \& Primavera, L. (2010). Supporting Authors in the Development of Task-Based Learning in Serious Virtual Worlds. British Journal of Educational Technology, 41(1), 86-107.

Boulos, M., Hetherington, L., \& Wheeler, S. (2007). Second Life: an overview of the potential of $3-D$ virtual worlds in medical and health education. Health Information and Libraries Journal, 24, 233-245. 
Chalk, P. (2002). Evaluating the Use of a virtual Learning Environment for Teaching Aspects of $\mathrm{HCl}$. Paper presented at the ITICSE '02, Aarhus Denmark.

Cheryan, S., Meltzoff, A. N., \& Kim, S. (2011). Classrooms Matter: the design of virtual classrooms influences gender disparities in computer science classes. Computers and Education, 57, 1825-1835.

Childs, M. (2007). Real Learning in Virtual Worlds. Warwick Interactions Journal, 30(2), 38-45.

Dawley, L. (2009). Social Network Knowledge Construction. On the Horizon, 17(2), 109-121.

Dieterle, E., \& Clarke, J. (Eds.). (2005) Encyclopedia of Multimedia Technology and Networking. Idea Group Publishing, Hershey, PA.

Edirisingha, P., Nie, M., Pluciennik, M., \& Young, R. (2009). Socialisation for learning at a distance in a 3-D multi-user virtual environment. British Journal of Educational Technology, 40(3), 458-479.

Falloon, G. (2010). Using Avatars and Virtual Environments in Learning: What do they have to offer? British Journal of Educational Technology, 41(1), 108-122.

Getchell, K., Miller, A., Allison, C., Kerbey, C., Hardy, R., Sweetman, R., et al. (2006). The LAVA Project: A Service Based Approach to Supporting Exploratory Learning. Paper presented at the IADIS International Conference WWW/Internet, Murcia, Spain

Getchell, K., Miller, A., Allison, C., \& Sweetman, R. (2008). Exploring the Second Life of a Byzantine Basilica. Paper presented at the Inspire Conference, Anglia Ruskin University, Cambridge.

Getchell, K., Miller, A., Nicoll, J. R., Sweetman, R., \& Allison, C. (2010). Games Methodologies and immersive Environments for Virtual Fieldwork. IEEE Trans. on Learning Technologies, 3(4), 281-293.

Gregory, S., Lee, M., Ellis, A., Gregory, B., Wood, D., Hillier, M., et al. (2010). Australian higher education institutions transforming the future of teaching and learning through $3 D$ virtual worlds. Paper presented at the Ascilite 2010, Sydney.

Hays, G. (2008). The social virtual world's a stage. Retrieved August 15, 2008, from http://www.personalizemedia.com/2008-metaverse-tour-video-the-social-virtualworlds-a-stage/

Hew, K. F., \& Cheung, W. S. (2010). Use of Three Dimensional (3-D) Immersive Virtual Worlds in K-12 and Higher Education Settings: A review of the research. British Journal of Educational Technology, 41(1), 33-55.

Jarmon, L., Traphagan, T., Mayrath, M., \& Trivedi, A. (2009). Virtual world teaching, experiential learning, and assessment: An interdisciplinary communication course in Second Life. Computers \& Education, 53, 169-182.

Jenkins, M., Browne, T., \& Walker, R. (2005). VLE surveys: A longitudinal perspective between March 2001, March 2003 and March 2005 for higher education in the United Kingdom. 
Retrieved 25 July 2008, from UCISA 2005,

http://www.immagic.com/eLibrary/ARCHIVES/GENERAL/UCISA_UK/U051130J.pdf

Jestice, R. J., \& Kahai, S. (2010, August 2010). The Effectiveness of Virtual Worlds for Education: An Empirical Study. Paper presented at the Sixteenth Americas Conference on Information Systems (AMCIS), Lima, Peru.

Joseph, B. (2007). Global Kids, Inc.'s Best Practices in using Virtual Worlds for Education. Paper presented at the SL Education Workshop Retrieved 25 July 2008 from http://slcc2007.wordpress.com/

Kay, J., \& FitzGerald, S. (2008). Educational Uses of Second Life. Retrieved July 5th, 2009, from http://sleducation.wikispaces.com/educationaluses

Kelle, S., \& García, R. M. C. (2007). Usability and Accessibility in Web 3D. Paper presented the UESS' 07. Retrieved 20 June 2008 from https://gradient.it.uc3m.es/filestorage/view/publications\%5C/uess07-rcg.pdf.

Kirkpatrick, D. (2007, February 5 2007). It's not a game. Fortune, 155. Retrieved 20 June 2008 from

http://money.cnn.com/magazines/fortune/fortune_archive/2007/02/05/8399120/index .htm

Leidl, M., \& Robling, G. (2007). How Will Future Learning Work in the Third Dimension? Paper presented at the ITiCSE' 07, Dundee, Scotland.

Macías-Díaz, A. (2008a). Report of Virtual Worlds in Education Conference at the University of Edinburgh. St Andrews: School of Management, University of St Andrews, St Andrews, Scotland

Macías-Díaz, A. (2008b). Survey of E-business Module (MN5553). School of Management, St Andrews University, St Andrews, Scotland

Mason, H. (2007, 24-26 Aug. 2007). Experimental Education in Second Life. Paper presented at the SLCC' 07, Chicago.

McKeown, L. (2007). Taking Action Learning Online in the 3D Virtual World of Second Life, International Review of Research in Open and Distance Learning, 8(3). Accessed 20 June 2008 from http://www.irrodl.org/index.php/irrodl/article/viewArticle/507/984

Mennecke, B. E. (2008). Second Life and other Virtual Worlds: A Roadmap for Research. Communications of the AIS, 22(20), 371-388.

Messinger, P. R., Eleni, S., \& Kelly, L. (2008). A Typology of Virtual Worlds. Jrnl of Virtual Worlds Research, 1(1), 1-18.

Myller, N., Bednarik, R., Sutinen, E., \& Ben-Ari, M. (2009). Extending the Engagement Taxonomy: Software Visualisation and Collaborative Learning. ACM Transactions on Computing Education, 9(1), 7:1 - 7:27. 
Oliver, M., \& Carr, D. (2009). Learning in virtual worlds: Using communities of practice to explain how people learn from play. British Journal of Educational Technology, 40(3), 444-457.

Pausch, R., \& Marinelli, D. (2007). Carnegie Mellon's Entertainment Technology Centre: Combining the Left and Right Brain. Communications of the ACM, 50(7), 50-57.

Petrakou, A. (2010). Interacting through Avatars: Virtual Worlds as a Context for Online Education. Computers and Education, 54, 1020-1027.

Porter, C. E. (2004). A Typology of Virtual Communities: A Multi-Displinary Foundation for Future Research. Journal of Computer-Mediated Communication, 10(1). Retrieved 10 March 2010 from http://onlinelibrary.wiley.com/doi/10.1111/j.1083-6101.2004.tb00228.x/full.

Richter, J., Anderson-Inman, L., \& Frisbee, M. (2007). Critical Engagement of Teachers in Second Life: Progress in the Salamadar Project. Paper presented at the SI Education Workshop, Chicago, Illinois

Rix, J., \& Twining, P. (2007). Exploring education systems: towards a typology for future learning? Educational Research, 49(4), 329-341.

Robbins, S. (2007). A Futurist's View of Second Life Education: A Developing Taxonomy of Digital Spaces. Paper presented at the SLCC 2007, Chicago, Illinois.

Roussou, M. (2004). Learning by Doing and Learning through Play: An Exploration of INteractivity in Virtual Environments for Children. ACM Computers in Entertainment, 2(1), 10-32.

Salmon, G. (2009). The future for (second) life and learning. British Journal of Educational Technology, 40(3), 526-538.

Smith-Robbins, S. (2011). Incommensurate Wor(l)ds: Epistemic Rhetoric and Faceted Classification of Communication Mechanics in Virtual Worlds. Ball State University, Munci, INdiana.

Sreedharan, S., Zurita, E., \& Plimmer, B. (2007). 3D Input for 3D Worlds. Paper presented the $\mathrm{OzCHI}$, Adelaide.

Sturgeon, T., Miller, A., \& Allison, C. (2009). 802.11 wireless experiments in a virtual world. Paper presented at ITICSE '09, Paris.

Trewin, S., Laff, M., Cavander, A., \& Hanson, V. (2008). Accessibility in Virtual Worlds. Paper presented at the $\mathrm{CHI}$ EA 08, Florence.

Twining, P. (2009). Exploring the Educational potential of Virtual Worlds - Some Reflections From the SPP. British Journal of Educational Technology, 40(3), 19, 416-514.

Warburton, S. (2009). Second Life in higher education: Assessing the potential for and the barriers to deploying virtual worlds in learning and teaching. British Journal of Educational Technology, 40(3), 13. 
Weusijana, D., Svihla, V., Gawel, D., \& Bransford, J. (2007). Learning about Adaptive Expertise in a Multi-User Virtual Environment. Paper presented at the Second Life Education Workshop 2007, Chicago.

Appendix: Literature Reviewed for Taxonomy

The Bibliography for all the analysed papers is at:

http://www.cs.st-andrews.ac.uk/ ishbel/Research/TaxonomyBiblio.pdf 